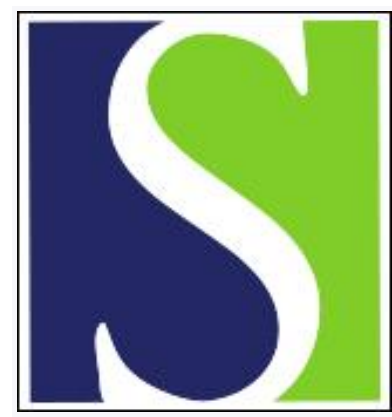

Scand J Work Environ Health 2010;36(6):466-472

https://doi.org/10.5271/sjweh.3120

Published online: 20 Sep 2010, Issue date: Nov 2010

Physical work demands, hypertension status, and risk of ischemic heart disease and all-cause mortality in the Copenhagen Male Study

by Holtermann A, Mortensen OS, Burr H, Søgaard K, Gyntelberg F, Suadicani P

Affiliation: National Research Centre for the Working Environment, Lersø Parkallé 105, 2100 Copenhagen Ø, Denmark. aho@nrcwe.dk

Refers to the following texts of the Journal: 2007;33(6):405-424 2010;36(5):357-365 2009;35(6):466-474 2003;29(5):363-377

The following article refers to this text: 2015;41(2):124-139

Key terms: all-cause mortality; cardiovascular health; Copenhagen Male Study; hypertension; hypertension status; IHD; ischaemic heart disease; ischemic heart disease; mortality; occupational health; occupational physical activity; physical demand; physical work demand; risk; work demand

This article in PubMed: www.ncbi.nlm.nih.gov/pubmed/20852831 


\title{
Physical work demands, hypertension status, and risk of ischemic heart disease and all-cause mortality in the Copenhagen Male Study
}

\author{
by Andreas Holtermann, PhD, ${ }^{1}$ Ole Steen Mortensen, PhD, ${ }^{1,2}$ Hermann Burr, PhD, ${ }^{1}$ Karen Søgaard, PhD, ${ }^{3}$ \\ Finn Gyntelberg, DMSc, ${ }^{2}$ Poul Suadicani, DMSc ${ }^{2}$
}

\begin{abstract}
Holtermann A, Mortensen OS, Burr H, Søgaard K, Gyntelberg F, Suadicani P. Physical work demands, hypertension status, and risk of ischemic heart disease and all-cause mortality in the Copenhagen Male Study. Scand J Work Environ Health. 2010;36(6):466-472.
\end{abstract}

\begin{abstract}
Objective Increased risk of ischemic heart disease (IHD) mortality from high physical work demands has been observed among men with low physical fitness and leisure time physical activity. We tested whether hypertensive men are at a particularly high risk of IHD mortality when exposed to high physical work demands.

Method We carried out a 30-year follow-up of the Copenhagen Male Study of 5249 gainfully employed men aged 40-59 years. Of these, 274 men with a history of myocardial infarction or prevalent symptoms of angina pectoris or intermittent claudication were excluded from the follow-up. Men were classified as having hypertension when any of the following factors was present: (i) treatment for hypertension, (ii) a systolic blood pressure of $>160 \mathrm{~mm} \mathrm{Hg}$, or (iii) a diastolic blood pressure of $>90 \mathrm{~mm} \mathrm{Hg}$. Physical work demands were determined by two self-reported questions.
\end{abstract}

Results Of the eligible study population, 587 men (11.9\%) died due to IHD. Hypertensive men had more than a doubled risk of IHD mortality [hazard ratio (HR) $2.16,95 \%$ confidence interval $(95 \% \mathrm{CI}) 1.80-2.59$ ]. Cox analyses - adjusted for age, smoking, alcohol, body mass index, diabetes, physical fitness, leisure time physical activity, and social class - showed that high physical work demands were associated with an increased risk of IHD and all-cause mortality among normotensive men ( $\mathrm{N}=4127$, HR 1.36, 95\% CI 0.96-1.92 and HR 1.24, 95\% CI 1.06-1.44, respectively), but not among the hypertensive men ( $\mathrm{N}=808$, HR $1.07,95 \% \mathrm{CI} 0.63-1.81$ and HR $1.07,95 \% \mathrm{CI} 0.80-1.42$, respectively) using men with low physical work demands as the reference.

Conclusion Compared to normotensive men, hypertensive men did not have a higher risk of IHD or all-cause mortality from high physical work demands.

Key terms cardiovascular health; IHD; occupational health; occupational physical activity.

In recent publications from the Copenhagen Male Study $(1,2)$, we showed that exposure to high physical work demands was associated with an increased risk of ischemic heart disease (IHD) mortality among men with low cardiorespiratory fitness and/or a low level of leisure time physical activity. The increased risk of IHD mortality associated with increasing work demands has been explained by a changed intravascular turbulence and arterial wall shear stress (3), inducing inflammatory processes in the arterial wall leading to atherosclerosis (4).

The prevalence of hypertension is high in industrial- ized populations like the US $(5,6)$ and a strong predictor of cardiovascular disease (CVD) and all-cause mortality (7). Since a high blood pressure induces an increased shear stress at the arterial wall, hypertensive men carrying out physically demanding work tasks (ie, lifting, carrying, pushing, and pulling) resulting in an additional increase in blood pressure (8), may be at a high risk of developing atherosclerosis and subsequently IHD death. Thus, in theory, such men would have a particularly increased risk of IHD mortality. This hypothesis has, to our knowledge, not previously been addressed.

1 National Research Centre for the Working Environment, Copenhagen, Denmark

2 The Copenhagen Male Study, Epidemiological Research Unit, Department of Occupational and Environmental Medicine, Bispebjerg University Hospital, Copenhagen NV, Denmark

3 Institute of Sports Science and Clinical Biomechanics, University of Southern Denmark, Odense M, Denmark

Correspondence to: Andreas Holtermann, National Research Centre for the Working Environment, Lersø Parkallé 105, 2100 Copenhagen Ø, Denmark. [E-mail: aho@nrcwe.dk] 


\section{Methods}

\section{Study population}

The Copenhagen Male Study was established in 19701971 and comprised 5249 (87\% of those invited to participate) male employees, aged 40-59 years, from 14 companies, covering the railway, public road construction, military, postal, telephone, customs, national bank, and medical industry sectors $(9,10)$.

The examination consisted of a questionnaire, a short interview, and a clinical examination including measurements of height, weight, and blood pressure. Indirect measurement of physical fitness [maximal oxygen consumption $\left.\left(\mathrm{VO}_{2} \mathrm{Max}\right)\right]$ was performed with a bicycle ergometer. Thirty-five men with orthopaedic problems, who were unable to perform the bicycle test, were excluded from the study.

From the questionnaire, we obtained information about working conditions, lifestyle, and general health, including history of myocardial infarction, angina pectoris, and intermittent claudication. The information given in the questionnaire was clarified with each subject in the ensuing interview. Details on the questionnaire have already been published (11). A number of these factors are elaborated in more detail below.

\section{Physical fitness}

Heart rate was measured during submaximal bicycle work in a steady state after at least six minutes of cycling with the aid of a stopwatch and stethoscope. The loads used were 100,150 , and $200 \mathrm{~W}$. One, two, or in a few cases three different loads were used. The load chosen in each case was determined by the weight and age of the person or heart rate during the first minute of the test; we determined the $\mathrm{VO}_{2} \mathrm{Max}$ using Åstrand's nomogram (12). The correlation between directly and indirectly measured $\mathrm{VO}_{2} \mathrm{Max}$ is high. The method used has previously been described in detail (9).

\section{Physical activity at work, general description}

Physical activity during work was estimated by the following question: "Which description most precisely covers your pattern of physical activity at work?" Groups were defined according to the following responses: (i) You are mainly sedentary and do not walk much around at your workplace, for example, desk work, and work including assembling of minor parts (group 1); (ii) You walk around quite a bit at your workplace but do not have to carry heavy items, eg, light industrial work, non-sedentary office work, inspection and the like (group 2); (iii) Most of the time you walk, and you often have to walk up stairs and lift various items. Examples include mail delivery and construction work (group 3); (iv) You have heavy physical work. You carry heavy burdens and carry out physically strenuous work, eg, work including digging and shoveling (group 4). In the analyses, physical activity was defined as follows: group $1=$ low, group $2=$ medium; group $3=$ high (since only $2.4 \%$ belonged to group 4 , groups 3 and 4 were pooled) and are referred to as high.

\section{Strenuous work}

Strenuous work was estimated from the question: "Do you perform strenuous work (work resulting in sweating)?" The answer options were: "often", "occasionally", and "seldom or never" and coded as follows: $1=$ seldom or never, $2=$ occasionally, and $3=$ often.

\section{Physical work activity, combined variable}

An additional variable was constructed in order to further distinguish between the presence or absence of physically demanding work. Summing up the values from the aforementioned questions on physical activity and strenuous work gave values ranging from 2-6. A low combined score of 2 was defined as "low physical work demands", a score of 3 or 4 was defined as "moderate physical work demands", and a score of 5 or 6 was defined as "high physical work demands".

\section{Physical activity in leisure time}

In order to determine this factor, the questionnaire asked "Which description most precisely covers your pattern of physical activity at leisure time?" with the following possible responses: (i) You are mainly sedentary, for example, you read, watch television, go to the cinema. In general you spend most of your leisure time performing sedentary tasks (group 1); (ii) You go for a walk, use your bicycle a little or perform activity for at least 4 hours per week, for example, light gardening, leisuretime building activity, table tennis and bowling (group 2); (iii) You are an active athlete, eg, run or play tennis or badminton for at least 3 hours/week. If you frequently perform heavy gardening, you also belong to this group (group 3); (iv) You take part in competitive sports, swim, play European football, handball or run long distances regularly several times per week (group 4).

In the analyses, the level of physical activity during leisure time was defined as group $1=$ low, group $2=\bmod -$ erate, and group $3=$ high (since only $0.4 \%$ belonged to group 4, groups 3 and 4 were pooled).

\section{Lifestyle factors}

The male workers reported if they were current smokers, previously smoked, or had never smoked. In addition, 
participants reported their daily average alcohol consumption as the number of alcoholic beverages consumed per day in the following categories: $0,1-2,3-5$, $6-10$, and $>10$.

\section{Clinical and health-related factors}

Based on height and weight measurements, body mass index (BMI) was calculated as $\mathrm{kg} / \mathrm{m}^{2}$. Blood pressure was measured with the subject seated and after 5-10 minutes rest. A $12 \mathrm{~cm}$ wide, $26 \mathrm{~cm}$ long cuff was firmly and evenly applied to the right upper arm with the lower edge of the cuff placed $2 \mathrm{~cm}$ antecubitally. Pressure was applied with quick inflation of the cuff to $200 \mathrm{mmHg}$ pressure or at least $30 \mathrm{mmHg}$ above systolic blood pressure. Deflation of the cuff was done with $2-3 \mathrm{mmHg}$ per pulse beat and diastolic blood pressure was recorded at disappearance of the sound. Taking into consideration the circumstances of the blood pressure measurements, in particular that the men were not at complete rest, we classified men as having hypertension when any of the following factors were present: (i) medical treatment for hypertension, (ii) a systolic blood pressure of $>160 \mathrm{~mm}$ $\mathrm{Hg}$, or (iii) a diastolic blood pressure of $>90 \mathrm{~mm} \mathrm{Hg}$. This classification meant that approximately $16 \%$ of the population analyzed in the prospective study was categorized as being hypertensive. The participants were asked if they received treatment due to hypertension from their physician or elsewhere. Answer options were yes and no. The participants were asked if they received treatment due to diabetes from their physician or elsewhere. Answer options were yes and no.

\section{Social class}

The men were divided into five social classes according to a system originally elaborated by Svalastoga and later adjusted by Hansen $(13,14)$. This classification system is based on education level and job position in terms of the number of subordinates. Typical jobs in the study cohort were: (i) officer, civil engineer, office executive, or head of department (social class I); (ii) head clerk or engineer (social class II); engine driver or train guard (social class III); machine fitter in a telephone company (social class IV); and unskilled laborer, mechanic, or driver (social class V).

\section{Eligibility}

In addition to the 35 men unable to carry out the bicycle test, men with a history of myocardial infarction $(\mathrm{N}=74)$, angina pectoris $(\mathrm{N}=165)$ or intermittent claudication $(\mathrm{N}=105)$ were excluded from the prospective study. In total, the excluded group comprised these 274 men and 9 men with missing answers, leaving 4943 men for the incidence study. With respect to all variables included, missing values ranged from $0-2.7 \%$.

\section{End-points}

We obtained information on death diagnoses between the period 1970-1971 to the end of 2001 from official national registers. The IHD mortality diagnoses included International Classification of Diseases' codes ICD-8: 410-14, and (from 1994) ICD-10: I20-I25.

\section{Statistical analysis}

We performed basic statistical analyses, Chi-squared analysis (likelihood ratio), unpaired t-test, and regression analyses. We estimated hazard ratios (HR) by $\exp (\beta)$, where $\beta$ is the hazard coefficient for the variable of interest in a Cox's proportional hazards regression model with the maximum likelihood ratio method. Assumptions regarding the use of Cox's proportional hazards were met by inspection of the $\log$ minus $\log$ function as the covariate mean. A varying number of men were included in the survival analysis due to differences in missing values for each particular analysis. We took, a priori, as significant a two-sided probability value of $\mathrm{P}<0.05$.

\section{Results}

Of the eligible study population of male workers, 591 died (11.9\%) from IHD mortality during the period 1970-1971 to 2001. During the same period, 2677 (54.1\%) male workers died in total.

Table 1 illustrates lifestyle and other characteristics stratified into low, moderate, and high occupational physical activity among male workers without history of myocardial infarction, angina pectoris, or intermittent claudication. A high level of occupational physical activity was strongly associated with the proportion of low social class (IV and V). Only minor, but statistically significant differences in level of leisure time physical activity were observed between male workers with different levels of occupational physical activity. Likewise, only minor but statistically significant differences in the degree of smoking were observed between male workers with different levels of occupational physical activity. However, a strong association was found for consumption of alcohol and occupational physical activity. No significant relations were seen between levels of occupational physical activity and age, BMI, diabetes, systolic and diastolic blood pressure, and hypertension. 
Table 1. Lifestyle and other characteristics according to physical work demands based on the combined activity variable (general physical work demands and strenuous work resulting in sweating) among men without history of myocardial infarction, angina pectoris, or intermittent claudication. [SD=standard deviation; freq=frequency; $\mathrm{VO}_{2} \mathrm{Max}=$ maximal oxygen consumption; $\mathrm{BP}=$ blood pressure.]

\begin{tabular}{|c|c|c|c|c|c|c|c|c|c|c|c|}
\hline & \multicolumn{9}{|c|}{ Level of physical work demands } & \multirow[t]{3}{*}{$\mathrm{Pa}$} & \multirow[t]{3}{*}{$P b$} \\
\hline & \multicolumn{3}{|c|}{ Low $(\mathrm{N}=1239)$} & \multicolumn{3}{|c|}{ Moderate $(\mathrm{N}=2661)$} & \multicolumn{3}{|c|}{ High $(\mathrm{N}=860)$} & & \\
\hline & Mean & SD & Freq $(\%)$ & Mean & SD & Freq $(\%)$ & Mean & SD & Freq $(\%)$ & & \\
\hline \multicolumn{12}{|l|}{ Physical fitness } \\
\hline Estimated $\mathrm{VO}_{2} \mathrm{Max}\left(\mathrm{ml} / \mathrm{min} / \mathrm{kg}^{-1}\right)$ & 32.6 & 7.1 & & 33.1 & 7.3 & & 33.9 & 7.4 & & $<0.001$ & 0.69 \\
\hline \multicolumn{12}{|l|}{ Lifestyle factors $1970-1971$} \\
\hline $\begin{array}{l}\text { Leisure-time physical activity } \\
\text { Low } \\
\text { Moderate } \\
\text { High }\end{array}$ & & & $\begin{array}{l}18.9 \\
70.4 \\
10.7\end{array}$ & & & $\begin{array}{r}15.6 \\
75.2 \\
9.2\end{array}$ & & & $\begin{array}{l}17.2 \\
69.3 \\
13.4\end{array}$ & 0.07 & $<0.001$ \\
\hline $\begin{array}{l}\text { Smoking } \\
\text { Current } \\
\text { Previous } \\
\text { Never }\end{array}$ & & & $\begin{array}{l}66.6 \\
22.4 \\
11.1\end{array}$ & & & $\begin{array}{r}72.2 \\
19.0 \\
8.8\end{array}$ & & & $\begin{array}{r}76.4 \\
15.6 \\
8.0\end{array}$ & $<0.001$ & $<0.001$ \\
\hline $\begin{array}{l}\text { Alcohol (beverages/day) } \\
0 \\
1-2 \\
3-5 \\
\geq 6\end{array}$ & & & $\begin{array}{r}38.8 \\
50.8 \\
9.2 \\
1.1\end{array}$ & & & $\begin{array}{r}34.3 \\
47.6 \\
15.4 \\
2.8\end{array}$ & & & $\begin{array}{r}25.9 \\
42.0 \\
25.1 \\
7.0\end{array}$ & $<0.001$ & $<0.001$ \\
\hline \multicolumn{12}{|l|}{ Clinical risk factors } \\
\hline Diabetes $^{c}$ & & & 0.9 & & & 0.6 & 1 & & 1.2 & 0.71 & 0.19 \\
\hline Systolic BP $(\mathrm{mm} \mathrm{Hg})$ & 134.8 & 18.5 & & 134.6 & 19.0 & & $\begin{array}{r}134.1 \\
0\end{array}$ & 19.5 & & 0.56 & 0.73 \\
\hline $\begin{array}{l}\text { Diastolic BP (mm Hg) } \\
\text { High blood pressure treatment }\end{array}$ & 83.3 & 11.5 & 1.9 & 82.8 & 11.4 & 1.6 & 82.9 & 11.7 & 1.5 & $\begin{array}{l}0.30 \\
0.51\end{array}$ & $\begin{array}{l}0.40 \\
0.78\end{array}$ \\
\hline Body mass index $\left(\mathrm{kg} / \mathrm{m}^{2}\right)$ & 24.7 & 2.8 & & 25.3 & 3.0 & & 25.9 & 3.1 & & $<0.001$ & 0.86 \\
\hline \multicolumn{12}{|l|}{ Other characteristics } \\
\hline Low social class (classes IV/N) & & & 21.7 & & & 58.9 & & & 91.3 & $<0.001$ & $<0.001$ \\
\hline Age (years) & 48.7 & 5.3 & & 48.6 & 5.3 & & 48.6 & 5.2 & & 0.73 & 0.66 \\
\hline
\end{tabular}

a P-values of trend test (Kendall's tau B) or test for linearity in analysis of variance.

${ }^{b}$ P-values of Chi-square test or test for deviation in analysis of variance.

${ }^{\mathrm{C}}$ Receives doctor's treatment due to diabetes.

Table 2 presents lifestyle and other characteristics according to hypertension among men without history of myocardial infarction, angina pectoris, or intermittent claudication. The hypertensive males had significantly lower fitness and different levels of leisure-time physical activity, smoking, and alcohol consumption, higher systolic and diastolic blood pressure, higher BMI, and were of an older age. No significant relationship was found between hypertension and social class.

Table 3 shows the association of baseline physical work demands, hypertension status, and physical fitness with risk of IHD mortality and all-cause mortality. Men with high physical work demands had a $69 \%$ increased risk of IHD mortality (age-adjusted HR $1.69,95 \%$ CI $1.31-2.17$ ) and a $51 \%$ higher risk of all-cause mortality (age-adjusted HR 1.51, 95\% CI 1.34-1.70) compared to men with low physical work demands. Hypertensive men had a more than two-fold $(116 \%)$ increased risk of IHD mortality (age-adjusted HR 2.16, 95\% CI 1.80-2.59), and a 58\% increased risk of all-cause mortality (age-adjusted HR 1.58, 95\% CI 1.44-1.74) compared to normotensive men.
Table 4 shows the risk of IHD and all-cause mortality during follow-up among normotensive and hypertensive men stratified according to level of physical work demands. Results of Cox proportional hazard analyses including different potentially confounding variables are presented. Among normotensive men, those with high physical work demands had a $65 \%$ increased risk of IHD mortality (HR 1.65, 95\% CI $1.20-2.27$ ) and a $40 \%$ increased risk for allcause mortality (HR 1.40, 95\% CI 1.21-1.61) when adjusted for all potential clinical and lifestyle-related confounders. Further inclusion of social class in the model, a factor per se strongly associated with physical work demands (table 1), attenuated the association to a $36 \%$ increased risk of IHD versus $24 \%$ for all-cause mortality.

Among the hypertensive men, those with high physical work demands had a non-significant increased risk of $57 \%$ of IHD mortality (HR $1.57,95 \%$ CI 0.98 2.52 ) and a non-significant $25 \%$ increased risk for allcause mortality (HR 1.25, 95\% CI 0.97-1.62) when adjusted for all potential clinical and lifestyle-related confounders. Further inclusion of social class also in 
Table 2. Lifestyle and other characteristics according to hypertension among men without history of myocardial infarction, angina pectoris, or intermittent claudication. [SD=standard deviation; freq=frequency; $\mathrm{VO}_{2} \mathrm{Max}=$ maximal oxygen consumption; $\mathrm{BP}=$ blood pressure.]

\begin{tabular}{|c|c|c|c|c|c|c|c|}
\hline & \multicolumn{6}{|c|}{ Hypertension status } & \multirow[t]{3}{*}{$\mathrm{Pa}$} \\
\hline & \multicolumn{3}{|c|}{$\begin{array}{l}\text { Hypertensives } \\
(\mathrm{N}=808 ; 16.4 \%)\end{array}$} & \multicolumn{3}{|c|}{$\begin{array}{l}\text { Normotensives } \\
(\mathrm{N}=4127 ; 83.6 \%)\end{array}$} & \\
\hline & Mean & SD & Freq $(\%)$ & Mean & SD & Freq $(\%)$ & \\
\hline \multicolumn{8}{|l|}{ Physical fitness } \\
\hline Estimated $\mathrm{VO}_{2} \mathrm{Max}\left(\mathrm{ml} / \mathrm{min} / \mathrm{kg}^{-1}\right)$ & 29.8 & 6.8 & & 33.7 & 7.2 & & $<0.001$ \\
\hline \multicolumn{8}{|l|}{ Lifestyle factors 1970-1971 } \\
\hline $\begin{array}{l}\text { Leisure-time physical activity } \\
\text { Low } \\
\text { Moderate } \\
\text { High }\end{array}$ & & & $\begin{array}{r}20.2 \\
72.3 \\
7.4\end{array}$ & & & $\begin{array}{l}16.2 \\
72.8 \\
11.0\end{array}$ & 0.01 \\
\hline $\begin{array}{l}\text { Smoking } \\
\text { Current } \\
\text { Previous } \\
\text { Never }\end{array}$ & & & $\begin{array}{l}62.6 \\
26.5 \\
10.9\end{array}$ & & & $\begin{array}{r}73.6 \\
17.6 \\
8.7\end{array}$ & $<0.001$ \\
\hline $\begin{array}{l}\text { Alcohol (beverages/day) } \\
0 \\
1-2 \\
3-5 \\
\geq 6\end{array}$ & & & $\begin{array}{r}30.7 \\
43.9 \\
20.3 \\
5.0\end{array}$ & & & $\begin{array}{r}34.4 \\
48.1 \\
14.8 \\
2.7\end{array}$ & $<0.001$ \\
\hline \multicolumn{8}{|l|}{ Clinical risk factors } \\
\hline $\begin{array}{l}\text { Diabetes b } \\
\text { Systolic BP (mm Hg) }\end{array}$ & 159.9 & 21.7 & 1.1 & 129.8 & 14.0 & 0.7 & $\begin{array}{r}0.19 \\
<0.001\end{array}$ \\
\hline Diastolic BP $(\mathrm{mm} \mathrm{Hg})$ & 101.3 & 10.0 & & 79.4 & 7.8 & & $<0.001$ \\
\hline $\begin{array}{l}\text { High blood pressure treatment } \\
\text { Body mass index }\left(\mathrm{kg} / \mathrm{m}^{2}\right)\end{array}$ & 26.7 & 3.3 & 9.8 & 25.0 & 2.8 & 0 & $<0.001$ \\
\hline \multicolumn{8}{|l|}{ Other characteristics } \\
\hline $\begin{array}{l}\text { Low social class (classes IVN) } \\
\text { Age (years) }\end{array}$ & 50.0 & 5.3 & 55.3 & 48.3 & 5.3 & 54.9 & $\begin{array}{r}0.83 \\
<0.001\end{array}$ \\
\hline
\end{tabular}

a P-values of Chi-square test (likelihood ratio) or Student's t-test.

${ }^{\mathrm{b}}$ Receives doctor's treatment due to diabetes.

Table 3. Risk of ischemic heart disease (IHD) mortality and all-cause mortality during 1970-1971 to end of 2001 according to physical work demands and hypertension status among men without history of myocardial infarction, angina pectoris or intermittent claudication at baseline. [HR=hazard ratio; $95 \% \mathrm{Cl}=95 \%$ confidence interval]

\begin{tabular}{|c|c|c|c|c|c|c|}
\hline & \multirow[t]{2}{*}{$\mathrm{N}$} & \multicolumn{2}{|c|}{ Mortality } & \multirow{2}{*}{$\begin{array}{l}\text { Incidence per } \\
100000 \text { person } \\
\text { years at risk }\end{array}$} & \multirow[t]{2}{*}{ Age-adjusted HR } & \multirow[t]{2}{*}{$95 \% \mathrm{Cl}$} \\
\hline & & N & $\%$ & & & \\
\hline \multicolumn{7}{|c|}{ Ischemic heart disease mortality } \\
\hline \multicolumn{7}{|c|}{ Physical work demands } \\
\hline Low & 1239 & 123 & 10.0 & 385 & $1.00 \mathrm{a}$ & \\
\hline Moderate & 2661 & 317 & 11.9 & 477 & 1.22 & $1.05-1.60$ \\
\hline High & 860 & 121 & 14.1 & 588 & 1.51 & $1.31-0.17$ \\
\hline \multicolumn{7}{|c|}{ Hypertension status } \\
\hline Normotensives & 4127 & 423 & 10.3 & 402 & $1.00^{a}$ & \\
\hline Hypertensives & 808 & 162 & 20.1 & 912 & 2.16 & $1.80-2.59$ \\
\hline \multicolumn{7}{|c|}{ All-cause mortality } \\
\hline \multicolumn{7}{|c|}{ Physical work demands } \\
\hline Low & 1239 & 598 & 48.5 & 1872 & $1.00^{a}$ & \\
\hline Moderate & 2661 & 1436 & 54.1 & 2164 & 1.22 & $1.11-1.34$ \\
\hline High & 860 & 532 & 60.8 & 2543 & 1.51 & $1.34-1.70$ \\
\hline \multicolumn{7}{|c|}{ Hypertension status } \\
\hline Normotensives & 4127 & 2093 & 51.0 & 1988 & $1.00^{\mathrm{a}}$ & \\
\hline Hypertensives & 808 & 566 & 70.1 & 3186 & 1.58 & $1.44-1.74$ \\
\hline
\end{tabular}

a Reference 
Table 4. Physical work demands and risk of ischemic heart disease (IHD) and all-cause mortality 1970-1971 to end of 2001 according to hypertension status. Different adjustment criteria are applied in Cox proportional hazards regression analyses with forced entry of variables. [HR=hazard ratios; $95 \% \mathrm{Cl}=95 \%$ confidence interval.]

\begin{tabular}{|c|c|c|c|c|c|c|c|c|c|c|}
\hline & $\mathrm{N}$ & $\begin{array}{c}\text { Crude } \\
\text { incidence } \\
(\%)\end{array}$ & $\mathrm{HR}^{\mathrm{a}}$ & $95 \% \mathrm{Cl}$ & $\mathrm{HR}^{\mathrm{b}}$ & $95 \% \mathrm{Cl}$ & $\mathrm{HR}^{\mathrm{c}}$ & $95 \% \mathrm{Cl}$ & $\mathrm{HR}^{\mathrm{d}}$ & $95 \% \mathrm{Cl}$ \\
\hline \multicolumn{11}{|l|}{ IHD mortality } \\
\hline Low work demands & 1011 & 8.0 & $1.00 \mathrm{e}$ & & $1.00^{e}$ & & $1.00^{e}$ & & $1.00^{e}$ & \\
\hline Moderate work demands & 2243 & 10.6 & $1.45^{f}$ & $1.13-1.87$ & $1.47^{\dagger}$ & $1.14-1.89$ & $1.38^{9}$ & $1.07-1.78$ & 1.25 & $0.95-1.64$ \\
\hline $\begin{array}{l}\text { High work demands } \\
\text { Hypertensives }\end{array}$ & 702 & 12.1 & $1.83^{h}$ & $1.35-2.48$ & $1.89^{h}$ & $1.39-2.57$ & $1.65^{f}$ & $1.20-2.27$ & 1.36 & $0.96-1.92$ \\
\hline Low work demands & 217 & 18.5 & $1.00 \mathrm{e}$ & & $1.00^{e}$ & & $1.00 \mathrm{e}$ & & $1.00 \mathrm{e}$ & \\
\hline Moderate work demands & 403 & 18.6 & 1.06 & $0.72-1.56$ & 1.06 & $0.72-1.56$ & 1.14 & $0.77-1.68$ & 0.90 & $0.59-1.36$ \\
\hline High work demands & 153 & 23.5 & 1.44 & $0.92-2.26$ & 1.43 & $0.92-2.25$ & 1.57 & $0.98-2.52$ & 1.07 & $0.63-1.81$ \\
\hline \multicolumn{11}{|l|}{$\begin{array}{l}\text { All-cause mortality } \\
\text { Normotensives }\end{array}$} \\
\hline Low work demands & 1011 & 44.2 & $1.00 \mathrm{e}$ & & $1.00^{e}$ & & $1.00^{e}$ & & $1.00^{e}$ & \\
\hline Moderate work demands & 2243 & 51.3 & $1.28^{\mathrm{h}}$ & $1.15-1.43$ & $1.29 \mathrm{~h}$ & $1.16-1.44$ & $1.22^{\mathrm{h}}$ & $1.09-1.36$ & $1.14 \mathrm{~g}$ & $1.01-1.28$ \\
\hline $\begin{array}{l}\text { High work demands } \\
\text { Hypertensives }\end{array}$ & 702 & 57.5 & $1.59^{\mathrm{h}}$ & $1.39-1.82$ & $1.64^{h}$ & $1.43-1.88$ & $1.40^{h}$ & $1.21-1.61$ & $1.24^{\dagger}$ & $1.06-1.44$ \\
\hline Low work demands & 217 & 67.6 & $1.00 \mathrm{e}$ & & $1.00 \mathrm{e}$ & & $1.00 \mathrm{e}$ & & $1.00^{\mathrm{e}}$ & \\
\hline Moderate work demands & 403 & 69.2 & 1.09 & $0.89-1.33$ & 1.09 & $0.89-1.33$ & 1.09 & $0.90-1.34$ & 1.00 & $0.80-1.24$ \\
\hline High work demands & 153 & 75.8 & 1.299 & $1.01-1.65$ & $1.29 \mathrm{~g}$ & $1.01-1.65$ & 1.25 & $0.97-1.62$ & 1.07 & $0.80-1.42$ \\
\hline $\begin{array}{l}\text { a Adjusted for age. } \\
{ }^{\mathrm{b}} \text { Adjusted for age + physical } \\
{ }^{\mathrm{C}} \text { Adjusted for age + potentia } \\
\text { leisure time physical activit } \\
{ }^{\mathrm{d}} \text { Adjusted for age + social } \mathrm{cl} \\
\text { never, previous), leisure tin } \\
{ }^{\mathrm{e}} \text { Reference. } \\
{ }^{\mathrm{f}} \mathrm{P}<0.01 \text {. } \\
{ }^{\mathrm{g}} \mathrm{P}<0.05 \text {. } \\
{ }^{\mathrm{h}} \mathrm{P}<0.001 \text {. }\end{array}$ & $\begin{array}{l}\text { fitness. } \\
\text { confoun } \\
y . \\
\text { ass + pot } \\
\text { e physic }\end{array}$ & $\begin{array}{l}\text { s: physica } \\
\text { ial confou } \\
\text { ctivity. }\end{array}$ & $\begin{array}{l}\text { ness, } \\
\text { rs: phy }\end{array}$ & $\begin{array}{l}\text { mass ind } \\
\text { fitness, }\end{array}$ & betes & $\begin{array}{l}\text { atment fo } \\
x, \text { diabete }\end{array}$ & $\begin{array}{l}\text { nol use, } \\
\text { nent for }\end{array}$ & $\begin{array}{l}\text { smoking (c } \\
\text { ), alcohol u }\end{array}$ & $\begin{array}{l}\text { never, } \\
\text { oking (c }\end{array}$ & $\begin{array}{l}\text { previous), } \\
\text { current, }\end{array}$ \\
\hline
\end{tabular}

this model, eradicated the association between physical work demands and IHD as well as all-cause mortality.

Because our a priori expectation was that hypertensive men would be at excessive risk of IHD mortality from high physical work demands, and this was not supported by the results, no interaction analyses were performed.

\section{Discussion}

The hypothesis that hypertensive men are at a higher risk for IHD and all-cause mortality than normotensive men when exposed to high physical work demands was rejected. Referencing men with low physical work demands, high physical work demands were associated with an increased risk of IHD mortality among normotensive but not hypertensive men. As expected, hypertensive men had a more than two-fold higher risk of IHD mortality, a finding consistent within all physical work demand groups. A similar, although slightly weaker relationship was found with respect to all-cause mortality.

The somewhat counterintuitive finding that physically demanding work not was associated with an increased risk of IHD and all-cause mortality among hypertensive men is not readily explained. However, considering the fact that hypertension induces an increased shear stress at the arterial wall, due to their condition, hypertensive men may already have sufficient shear stress at their arterial walls at rest. So, the modulated shear stress induced by a high workload, may have no additional effect on their a priori elevated risk.

From a preventive occupational, clinical, and public health point of view, the results of the present study suggest that hypertensive men, in contrast to what should be expected, do not constitute a particularly vulnerable group when exposed to physically demanding work tasks.

\section{Methodological considerations}

A methodological aspect of this study is that the information regarding physical work demands was based on self-assessment, which invariably entails some degree of misclassification (15). However, no technical equipment for measuring daily physical activity at work and in leisure was available in 1970, at least not in Denmark. In addition, the lack of continuous exposure data and repeated measures of exposure during the relatively long follow-up period may have contributed 
to misclassification of exposure. Estimation of physical fitness with Åstrand's nomogram is not valid among persons taking beta-blocker medicine. This was not a problem in this study because of the very few men taking beta-blockers $(\mathrm{N}=36)$. Due to the lack of data on serum cholesterol, adjustment for this risk factor for cardiovascular disease was not possible.

The study population of the Copenhagen Male Study is urban Danish male workers between 40-59 years of age in 1970-1971. It is unknown whether the findings of this study are relevant also for females, younger workers, self-employed or workers from other (eg, rural) communities or of other nationalities. Moreover, the workers with pre-existing CVD were excluded from this study.

\section{Concluding remarks}

Considering the fact that both phenomena [ie, hypertension $(5,6)$ and high physical work demands $(3$, 16)] are frequent in Western societies and in the world as a whole, the findings in this study may be broadly relevant. Irrespective of their physical work demands, hypertensive men had a doubled risk of IHD and a forty percent increased risk of all-cause mortality. From a preventive occupational, clinical, and public health point of view, the results of the present study suggest that hypertensive men do not constitute a particularly vulnerable group when exposed to physically demanding work tasks.

\section{Acknowledgement}

This study was financed by the Danish Working Environment Research Foundation

\section{References}

1. Holtermann A, Mortensen OS, Burr H, Søgaard K, Gyntelberg F, Suadicani P. The interplay between physical activity at work and during leisure time - risk of ischemic heart disease and allcause mortality in middle-aged Caucasian men. Scand J Work Environ Health. 2009;35(6):466-74.

2. Holtermann A, Mortensen OS, Burr H, Søgaard K, Gyntelberg F, Suadicani P. Physical demands at work, physical fitness, and 30-year ischemic heart disease and all-cause mortality in The Copenhagen Male Study. Scand J Work Environ Health. 2010;36(5):357-65.
3. Krause N, Brand RJ, Kaplan GA, Kauhanen J, Malla S, Tuomainen T-P, et al. Occupational physical activity, energy expenditure and 11-year progression of carotid atherosclerosis. Scand J Work Environ Health. 2007;33(6):405-424.

4. Glagov S, Zarins C, Giddens DP, Ku DN. Hemodynamics and atherosclerosis - Insights and perspectives gained from studies of human arteries. Archives of Pathology \& Laboratory Medicine. 1988;112(10):1018-1031.

5. Fields LE, Burt VL, Cutler JA, Hughes J, Roccella EJ, Sorlie P. The burden of adult hypertension in the United States 1999 to 2000 - A rising tide. Hypertension. 2004;44(4):398-404.

6. Wang YF, Wang QJ. The prevalence of prehypertension and hypertension among US adults according to the new Joint National Committee guidelines. Archives of Internal Medicine. 2004;164(19):2126-2134.

7. Lewington S, Clarke R, Qizilbach N, Peto R, Collins R. Age-specific relevance of usual blood pressure to vascular mortality: a meta-analysis of individual data for one million adults in 61 prospective studies. Lancet. 2002;360:1903-1913.

8. Åstrand I, Guharay A, Wahren J. Circulatory responses to arm exercise with different arm positions. Journal of Applied Physiology. 1968;25(5):528-532.

9. Gyntelberg F. Physical fitness and coronary heart-disease male residents in Copenhagen aged 40-59. Danish Medical Bulletin. 1973;20(1):1-4.

10. Gyntelberg F. One-year and 2-years incidence of myocardialinfarction in Copenhagen males aged 40-59. Danish Medical Bulletin. 1975;22(2):81-84.

11. Hein HO, Suadicani P, Gyntelberg F. Ischemic heart disease incidence by social class and form of smoking: the Copenhagen Male Study-17 years' follow-up. Journal of Internal Medicine. 1992;231(5):477-483.

12. Åstrand P-O, Rodahl K. Textbook of work physiology. Physiological bases of exercise. New York: McGraw-Hill Book Company; 1986.

13. Svalastoga K. Prestige, class and mobility. Copenhagen: Munksgaard; 1959.

14. Hansen EJ. Social groups in Denmark. Copenhagen: The Danish National Centre for Social Research; 1984.

15. Sallis JF, Saelens BE. Assessment of physical activity by self-report: Status, limitations, and future directions. Research Quarterly For Exercise And Sport. 2000;71(2):S1-S14

16. Karlqvist LK, Harenstam A, Leijon O, Scheele P. Excessive physical demands in modern worklife and characteristics of work and living conditions of persons at risk. Scand J Work Environ Health. 2003;29(5):363-377.

Received for publication: 4 June 2010 